\title{
Acid generation potential and metal(loid) release from resuspended sulfidic mine waste
}

\author{
JILLIAN R HELSER ${ }^{1}$, ANA LUPU ${ }^{2}$ AND VALÉRIE \\ CAPPUYNS $^{1}$
}

${ }^{1}$ KU Leuven

${ }^{2}$ University of Parma

Presenting Author: jillian.helser@kuleuven.be

Sulfidic mine waste exposed to oxidation can generate acidity and leach metal(loid)s into the environment, posing a risk to surrounding ecosystems and human health. To evaluate the risks for specific cases, experimental studies to determine the acid generation potential and mobilization of metal(loid)s are necessary. In the present study four sulfidic mine waste samples were investigated. One sample (mine tailings, FR_01) is from a former $\mathrm{Cu}-\mathrm{Pb}-\mathrm{Zn}$ mine in the Freiberg mining district (Germany) and the other three samples, which consist of a fresh waste rock sample (NC_01), fresh tailings (NC_02) and stored waste rock (NC_03), are from a currently operational $\mathrm{Cu}-\mathrm{Zn}$ mine in the Iberian Pyrite Belt of Portugal. Mineralogical characterization of the samples was performed by X-ray diffraction (XRD), optical microscopy, and a scanning electron microscope with energydispersive X-ray spectroscopy (SEM-EDS). Additionally, a resuspension experiment was performed to study the acid generation potential of the samples, as well as the effect of oxidation on the release of hazardous elements. Geochemical modelling and an acid-base accounting test were also used to gain more insight into the resuspension experiment and model the even longer-term leaching behavior of the mine waste samples. The mineralogical study revealed the presence of sulfide minerals (e.g., pyrite, arsenopyrite, chalcopyrite, and sphalerite) both as free particles and embedded within other minerals (e.g., quartz). The resuspension experiment, in which the mine waste is continuously agitated with water, has -been ongoing for 1.5 years and exhibits the acid generation potential of the samples, which all currently have a $\mathrm{pH}<3$. The resuspension of the mine waste in water also resulted in a considerable release of $\mathrm{As}, \mathrm{Cu}, \mathrm{Pb}$ and $\mathrm{Zn}$. Based on the results, it is evident that the samples pose a threat to the environment. Therefore, different remediation methods were considered to minimize the environmental risks. 